\title{
Considerações sobre os discursos do aconselhamento nos centros de testagem anti-HIV
}

SOUZA, V.; CZERESNIA, D. Counseling discourse in anti-HIV testing services. Interface - Comunic., Saúde, Educ., v.11, n.23, p.531-48, set/dez 2007.

This article analyzes the incorporation of counseling practice into anti-HIV testing service as the result of a social discursive construction of AIDS in the context of late modernity and based on a proposal by the Brazilian STD/ AIDS National Program. The main analytical references were the global influences in democratization process of modern practices and discourses contextualized by Fairclough. Other references were the evolution of preventive discourses broadcasted since the infection was first identified, and disciplinary power and confession technologies. Counseling includes major themes such as 'technologization', reflexivity, and dialogue. In this practice a game of ambiguities can be identified between the democratic and coercive systems which conjugate liberating and disciplinary modes. Understanding counseling from the vantage point of this ambiguity is to deal with issues still little investigated. It is necessary to understand counseling practice from the user's point of view, inasmuch as he/she is the end recipient of this practice.

KEY WORDS: Counseling. Acquired Immunodeficiency Syndrome. Health education.

O objetivo do trabalho foi analisar a incorporação da prática de aconselhamento nos centros de testagem antiHIV, como decorrência da construção discursivo-social da AIDS, no contexto da modernidade tardia e com base na proposição expressa pelo Programa Nacional de DST/AIDS do Brasil. Como principal referência analítica, foram tomadas as influências globais no processo de democratização dos discursos e das práticas modernas, contextualizadas por Fairclough. Utilizou-se também como referência teórica a evolução dos discursos preventivos veiculados desde a identificação da infecção e as tecnologias de poder disciplinar e de confissão. $\mathrm{O}$ aconselhamento contempla temas importantes, como tecnologização, reflexividade e diálogo. Pode-se identificar, nele, um jogo de ambigüidades entre os sistemas democrático e coercitivo, conjugando modos liberadores $e$ disciplinares. Compreender o aconselhamento sob o ponto de vista dessa ambigüidade gera questionamentos ainda pouco investigados. É necessário entender a prática do aconselhamento do ponto de vista do usuário, a quem a proposta é dirigida.

PALAVRAS-CHAVE: Aconselhamento. Síndrome de Imunodeficiência Adquirida. Educação em saúde.

${ }^{1}$ Graduada em Enfermagem e Obstetrícia; doutora em Ciências; professora, departamento de Enfermagem Materno-Infantil e Saúde Pública, Escola de Enfermagem, Universidade Federal de Minas Gerais. Belo Horizonte, MG. <vaniaxsouza@yahoo.com.br> ${ }^{2}$ Médica; doutora em Saúde Pública; pesquisadora, departamento de Epidemiologia, Escola Nacional de Saúde Pública Sérgio Arouca, Fundação Oswaldo Cruz. Rio de Janeiro, RJ. <dina@ensp.fiocruz.br> 


\section{Introdução}

Em 1981 foram identificados, nos Estados Unidos, os primeiros casos do que viria a ser denominada a Síndrome da Imunodeficiência Humana (AIDS). Após mais de vinte anos de epidemia, as possibilidades de controle efetivo do HIV/ AIDS ainda parecem remotas (Ceccato et al., 2004). No Brasil, tornou-se objetivo e desafio das políticas oficiais do Ministério da Saúde (MS), uma maior consciência e autonomia da população para a tomada de decisão frente à infecção pelo HIV, assim como às Doenças Sexualmente Transmissíveis (DST).

Nos últimos anos, uma das prioridades do Programa Nacional de DST/AIDS (PN-DST/AIDS) foi incluir práticas de prevenção nas atividades assistenciais já existentes nos serviços de saúde e a incorporação do aconselhamento em todos os serviços de atendimento em DST/AIDS e Centros de Testagem anti-HIV (CTA) (Brasil, 2004a, 1999a).

As etapas do aconselhamento são compostas de fases preestabelecidas $e$ interligadas que visam: a quebra da cadeia de transmissão; o auxílio à busca de alternativas para a prevenção das DST/HIV e AIDS; a adesão ao tratamento e o atendimento de parceiro(s) sexuai(s) (Brasil, 1999a, 1999b). Segundo o Ministério da Saúde (MS), o aconselhamento é definido como:

\footnotetext{
um diálogo baseado em uma relação de confiança que visa proporcionar à pessoa condições para que avalie seus próprios riscos, tome decisões $e$ encontre maneiras realistas de enfrentar seus problemas relacionados às DST/HIV/Aids. (Brasil, 2004a)
}

O aconselhamento, como uma estratégia de prevenção, formula discursos que propõem a reflexão, superação de dificuldades no enfrentamento dos problemas relacionados às DST/HIV/AIDS e adoção de medidas preventivas na busca de uma melhor qualidade de vida. Esses discursos não apenas refletem relações sociais, mas as constroem e posicionam as pessoas de diversas maneiras como sujeitos sociais - por exemplo, como médicos ou pacientes (Fairclough, 2001).

A análise do desenvolvimento histórico das formas de significação da epidemia indica mudanças nos discursos e práticas sociais, tanto no contexto das políticas públicas como dos movimentos sociais organizados. A proposta institucional do aconselhamento ocorre em uma época marcada por profundas transformações sociais. Estas se relacionam a modos de comportamento estabelecidos pelo mundo industrializado que se tornaram mundiais em seu impacto (Giddens, 2002). Giddens denomina de modernidade tardia este período da contemporaneidade, marcado por uma consciência crescente da descontinuidade, da diferença, da necessidade do diálogo e da polifonia. Polifonia diz respeito ao conjunto de vozes - explícitas ou implícitas - que se justapõem ou dialogam, tornando o enunciado um elo de cadeia complexa de outros enunciados (Bakhtin, 1997).

O objetivo deste artigo foi analisar, com base na proposição expressa pelo PN-DST/AIDS, a incorporação da prática de aconselhamento nos serviços de testagem anti-HIV, como decorrência da construção discursivo-social da AIDS, no contexto da modernidade tardia. Para isso, como principal referência 
analítica, foram tomadas as influências globais no processo de democratização dos discursos e das práticas modernas, contextualizadas por Fairclough (2001). utilizou-se também como referência teórica a evolução dos discursos preventivos veiculados segundo periodização da epidemia, concepções e práticas prevalentes, conforme Ayres et al. (2003) e as tecnologias de poder disciplinar e de confissão apresentadas por Foucault (2006, 2005a), como técnicas de controle dos corpos e que constituem hábitos.

Compreender o contexto histórico-social do aconselhamento nos serviços de testagem pode contribuir para dimensionar seus objetivos e estratégias de ação. $O$ aconselhamento é uma prática em construção que apresenta desde problemas técnico-estruturais até a dificuldade de se avaliar, de forma consistente, o efeito nos usuários (Araújo, 2003a; Brasil, 1999a; Filgueiras \& Deslandes, 1999; Minayo et al., 1999).

\section{Discurso, sociedade e modernidade}

Os discursos são práticas, não apenas de representação, mas também, de organização do mundo e têm conexões com os sistemas ideológicos e de poder de uma determinada sociedade. São formações de saberes com regras próprias $e$ inseridas em sistemas de poder (Foucault, 2005b). O poder se configura como estratégias, manobras, táticas, técnicas e funcionamentos e mais se exerce do que se possui. Nesse sentido, trabalhamos com um conceito móvel de poder, que gera efeitos e se localiza nas relações. Poder e saber estão diretamente implicados e "não há relação de poder sem constituição correlata de um campo de saber, nem saber que não suponha e não constitua ao mesmo tempo relações de poder" (Foucault, 2006, p.27).

Os discursos contribuem para

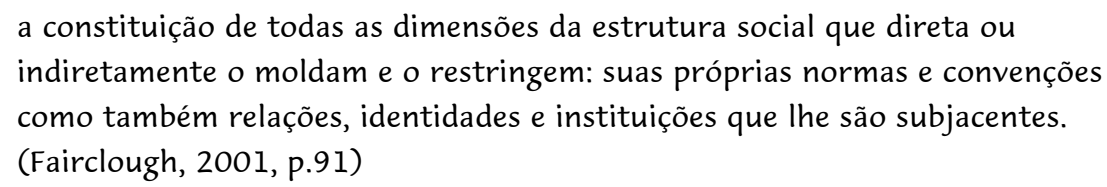

Para Fairclough, os discursos são constitutivos de identidades sociais, relações sociais e sistemas de conhecimento e crença. Por identidades sociais entendemse todos os sistemas de representação, ao se referirem, por exemplo, a pobres ou ricos, homossexuais ou heterossexuais. Por relações sociais compreende-se o sistema que constitui a base de relacionamento entre os sujeitos, que pode ser familiar, profissional, casual, etc. Como sistema de conhecimento e crença, podem-se citar aqueles que vão desde os aspectos do senso comum até os postulados científicos, tomando-se como exemplo a cura por meio da fé, reconhecida no senso comum, e a refutação científica de qualquer tipo de tratamento que não seja passível de confirmação clínica ou laboratorial.

Por isto, analisar os discursos como modo de ação implica o estabelecimento de uma relação dialética entre o discurso e a estrutura social. A articulação dos discursos, neste nível, sugere que eles são de importância central nos processos da sociedade moderna.

Fairclough (2001) enfatiza algumas tendências que têm influenciado as 
práticas modernas associadas às instituições ou a domínios particulares, tais como a relação médico-paciente, professor-aluno, pais-filho e o próprio aconselhamento. $\mathrm{O}$ autor considera surpreendente como se tem dado pouca atenção a essas tendências de mudança nas ordens do discurso, destacando a democratização e tecnologização, que têm causado um impacto notável sobre a ordem do discurso contemporâneo.

Enquanto

a democratização refere-se a mudanças efetivas nas práticas de discurso, a tecnologização sugere que a intervenção consciente nas práticas discursivas é um fator cada vez mais importante na produção de mudança. (Fairclough, 2001, p.247)

Essas tendências interagem entre si e figuram processos de luta hegemônica de impacto desigual e contrastes claros entre ordens do discurso locais, associadas a instituições, ou a domínios particulares e de diferentes localidades. Segundo o autor, a prática discursiva manifesta-se em forma lingüística, que envolve o processo de produção, distribuição e consumo textual (linguagem falada ou escrita). "Todos esses processos são sociais e exigem referência aos ambientes econômicos, políticos e institucionais particulares nos quais o discurso é gerado" (Fairclough, 2001, p.99). Assim, a natureza desses processos varia entre diferentes tipos de discurso segundo sua relação com as estruturas e lutas sociais.

Fairclough (2001) entende por 'democratização' a retirada de desigualdades e assimetrias de direitos, obrigações e prestígio discursivo dos grupos de pessoas. Cinco áreas de democratização discursiva são por ele destacadas, quais sejam: relações entre línguas e dialetos sociais; acesso a tipos de discurso de prestígio; eliminação de marcadores explícitos de poder em tipos de discurso institucionais com relações desiguais de poder; uma tendência à informalidade das línguas; e mudanças nas práticas referentes ao gênero na linguagem.

A segunda tendência, ou seja, a tecnologização, configura-se como o conjunto de instrumentos que podem ser usados para conseguir uma variedade ampla de estratégias em muitos e diversos contextos. Um exemplo disto são as tecnologias do discurso, tais como: a entrevista, o ensino, o aconselhamento e a publicidade (Fairclough, 2001).

$\mathrm{O}$ aconselhamento como uma prática contemporânea recebeu o status de uma instituição organizadora de sistemas de poder ideologicamente localizados (Fairclough, 2001). Refletir sobre a prática do aconselhamento à luz desses conceitos significa entender como diferentes discursos se combinam, em condições sociais particulares, para constituir um novo discurso e um novo saber.

\section{As transformações discursivas sobre a AIDS}

Ao final dos anos 1970 e início dos anos 1980, surgiram, nos Estados Unidos, os primeiros óbitos devidos a uma doença desconhecida, associada à comunidade gay das cidades de São Francisco, Los Angeles e Nova Iorque. A 
primeira forma de denominação da infecção foi "câncer gay", "peste gay" ou ainda "peste rosa", alusão ao símbolo dessa cor utilizado pelos nazistas para identificar os homossexuais nos campos de concentração durante a II Guerra Mundial (Simões, 1997).

Posteriormente aos homossexuais, os hemofílicos, haitianos e os heroinaddicts - os chamados quatro Hs - foram coligados como os grupos acometidos pela "nova doença" (Ayres et al., 2003; Monteiro, 2002; Simões, 1997). A forma como os sujeitos foram interpelados pelo discurso médico da época associava a infecção a grupos específicos de gênero, etnia, práticas sexuais $e$ estilos de vida, estigmatizando-os e dicriminando-os.

As tentativas iniciais de resposta à infecção entre 1981 e 1984, definidas por Mann e Tarantola (1996 apud Ayres et al., 2003) como a primeira fase, focalizaram esses indivíduos (os quatro Hs) constituindo os chamados "Grupos de Risco". Caracterizou-se, assim, uma divisão entre inocentes e culpados que não deveriam ter relações sexuais, doar sangue e/ou usar drogas injetáveis. Uma falsa segurança foi também provocada entre pessoas não pertencentes aos grupos de risco, tornando-as mais vulneráveis.

Foi instalado um discurso preventivo-normativo e homofóbico, prevalecendo uma abordagem alarmista, com ênfase na informação e participação da mídia. Além dos êxitos técnicos com a identificação do vírus e a descoberta do teste sorológico, as estratégias iniciais de combate à infecção produziram, em grande escala, estigma, medo e preconceito (Ayres et al., 2003).

Na segunda fase, entre 1985 e 1988, houve um deslocamento do discurso de grupo de risco para o de "Comportamento de Risco". Isso aconteceu diante do caráter epidêmico da AIDS, das pressões geradas por grupos sociais e das transformações no perfil epidemiológico da infecção, com o acometimento de indivíduos de ambos os sexos, de diferentes regiões, condições econômicas e orientação sexual (Ayres et al., 2003).

O enfoque no comportamento de risco era uma resposta à inadequação do uso de medidas preventivas restritas a grupos específicos (Ayres et al., 2003). o objetivo era retirar o peso do estigma dos grupos de risco, universalizar a preocupação com o controle da infecção e envolver os indivíduos com a prevenção (Ayres et al., 2003). As estratégias de intervenção foram direcionadas a esse novo público e fundamentadas em atitudes e discursos menos punitivos, focalizados no estabelecimento de práticas seguras de prevenção à infecção, como o uso do preservativo em todas as relações sexuais.

O discurso de comportamento de risco, embora fosse inequivocamente mais abrangente que o de grupo de risco, não correspondeu ao esperado em termos de mudança de atitude e de comportamento da população (Ayres et al., 2003; Mann et al., 1993; Simões, 1997). Além disso, amenizava, mas não excluía os aspectos discriminatórios e estigmatizantes, introduzidos anteriormente, na medida em que a prevenção se mantinha focada em conduta, hábitos e práticas sexuais.

Essa temática, ainda direcionada ao risco e sob a ótica do indivíduo, foi motivo de críticas, por sua tendência a colocar o sujeito como o único responsável pela falha ou sucesso na prevenção da infecção (Ayres et al., 2003; Brasil, 1999b). O movimento social organizado, especialmente o dos direitos das mulheres, apresentou as mais expressivas críticas ao conceito de 
comportamento de risco. Com a noção de 'empoderamento' (empowerment), buscava-se deslocar o discurso preventivo embasado no conceito de práticas $e$ comportamentos de risco para o incremento do poder de decisão e cidadania (Ayres et al., 2003; Monteiro, 2002; Parker, 2000).

As modificações no perfil da dinâmica da epidemia, caracterizada pelos chamados processos de feminilização, pauperização, juvenilização $e$ interiorização da AIDS, estimularam a reflexão sobre a necessidade de mudanças estruturais e respostas a setores sociais menos favorecidos (Ayres et al., 2003; Mattos, 2003; Souza \& Freitas, 2002; Parker, 2000; Parker \& Camargo Jr., 2000; Simões, 1997).

$\mathrm{O}$ debate desses novos temas marcou a terceira e atual fase de resposta à epidemia, que se inicia em 1989, sob o propósito inédito de um deslocamento das intervenções comportamentais baseadas em informações objetivas $e$ na persuasão racional para um enfoque de capacitação coletiva e de mobilização comunitária vinculado às condições políticas, econômicas, sociais, culturais $e$ simbólicas de existência.

Esse foi um momento de grande contribuição das Organizações NãoGovernamentais - ONGs que, junto com os setores acadêmicos, grupos ativistas, pesquisadores e outros profissionais, se envolveram no aprofundamento das estratégias de intervenção social e estrutural de resposta à infecção (Ayres et al., 2003). Várias organizações já existentes, em especial as organizações gays e outras recém-surgidas de apoio religioso e de pessoas infectadas pelo vírus, concentraram-se especificamente na AIDS, com atividades de prevenção, educação, no fortalecimento de serviços/assistência às pessoas infectadas, assim como, no monitoramento crítico das políticas públicas e na defesa das liberdades e direitos civis (Parker, 1994).

Nesse contexto, o conceito de vulnerabilidade se desenvolveu, ganhou força e gerou a necessidade de uma visão mais ampliada e reflexiva para o controle da infecção. Por vulnerabilidade entende-se:

\footnotetext{
O movimento de considerar a chance de exposição das pessoas ao adoecimento como a resultante de um conjunto de aspectos não apenas individuais, mas também coletivos, contextuais, que acarretam maior suscetibilidade à infecção $e$ ao adoecimento $e$, de modo inseparável, maior ou menor disponibilidade de recursos de todas as ordens para se proteger de ambos. (Ayres et al., 2003, p.123)
}

As intervenções não estariam restritas ao HIV, mas relacionadas aos três elementos primordiais: informação e educação; serviços de saúde e sociais; $e$ ambiente social apropriado (Mann et al., 1993). No campo da diagnose, prognose e terapêutica, a técnica da contagem de carga viral, a avaliação via contagem de linfócitos CD4, somada ao advento da terapia combinada de alta potência - Highly Active Antiretroviral Therapy - (HAART), com grande impacto sobre as taxas de morbimortalidade, não corresponderam ao esperado no controle da epidemia (Ayres et al., 2003). Embora o tratamento e a precocidade do diagnóstico possam contribuir para a redução do número de novos casos, esse resultado só é possível quando associado às práticas preventivas. 
A prevenção com enfoque em modelos multidimensionais de alcance social $e$ estrutural, de conscientização coletiva e mobilização comunitária reafirmou-se como central no controle da epidemia (Ayres et al., 2003; Parker, 2000; Parker E Camargo Jr., 2000).

As ações preventivas voltaram-se para atender, de forma mais satisfatória, à demanda do indivíduo-coletividade, cedendo lugar às chamadas estratégias de Redução de Riscos, fundamentadas na difusão de informação, controle de bancos de sangue, práticas de "sexo mais seguro", testagem e aconselhamento. Para os usuários de drogas injetáveis desenvolveu-se o programa de Redução de Danos, com a polêmica distribuição ou troca de agulhas e seringas (Ayres et al., 2003).

O discurso de vulnerabilidade é, portanto, mais inclusivo e aparece marcado pela tendência da democratização. Incorpora temas relacionados com a educação e direitos humanos. Reduz assimetrias, amplia e fortalece a prática de aconselhamento como uma medida de prevenção que responde às especificidades dos sujeitos independentemente de sua condição sorológica, grupo social ou orientação sexual.

\section{A oferta de testes sorológicos e a prática de aconselhamento no Brasil}

Sob o impacto epidemiológico-social da AIDS foi criado, em 1985, por meio de portaria ministerial, o PN-DST/AIDS, oficialmente iniciado em 1986 (Brasil, 2007; Araújo, 2003b; Simões, 1997). Em 1987, os exames sorológicos para detecção de anticorpos do HIV foram disponibilizados na rotina de bancos de sangue e nos serviços de referência para tratamento dos doentes com AIDS. Denominados Centros de Testagem Anônima (CTA), esses serviços de referência tinham, por objetivo, determinar a prevalência da infecção na comunidade $e$ obter confirmação diagnóstica das diferentes formas clínicas da infecção.

O termo aconselhamento, então muito pouco utilizado, era citado apenas no caso específico de atendimento aos indivíduos com resultado do teste anti-HIV confirmado (Araújo, 2003b). Devido às carências dos serviços de saúde especializados no atendimento aos portadores do vírus, a prática de apoio e aconselhamento passou a ser desenvolvida pelas recém-surgidas ONGs e se expandiu para diversos segmentos populacionais e entre grupos de pessoas diretamente atingidas pela epidemia (Brasil, 1999b). Esse movimento gerou matrizes de solidariedade e novas formas de atuação política em defesa das pessoas vivendo com HIV/AIDS e em questões cruciais das políticas públicas (Silva, 1998).

Em seguida, começou a ser estimulada a criação, em âmbito nacional, dos Centros de Orientação e Apoio Sorológico, que ficaram conhecidos pelo nome de COAS (Araújo, 2003b; Brasil, 1999b). O primeiro deles, localizado no Rio Grande do Sul, foi implantado em 1988.

A equipe de trabalho foi definida como multidisciplinar, com profissionais com experiência na área, como enfermeiros, médicos, profissionais de saúde mental, assistentes sociais, educadores e outros (Araújo, 2003b; Brasil, 1999a, 1999b). Instrutores dos Centros de Referência ficaram responsáveis pelo treinamento dos profissionais de saúde que teriam o compromisso de reproduzi-lo em seu Estado (Araújo, 2003b). 
O objetivo do COAS era desviar a demanda dos bancos de sangue e criar uma modalidade alternativa de serviço de saúde para o oferecimento de sorologia anti-HIV, de forma gratuita, confidencial e anônima, a fim de facilitar o acesso à realização do teste (Costa, 2004; Araújo, 2003b; Brasil, 1999b). Ao mesmo tempo, tinha o intuito de prover orientação sobre a infecção e modos de prevenção do HIV. A prática de aconselhamento, ainda incipiente, era uma tentativa de redução de comportamentos de risco. $\mathrm{O}$ serviço também possibilitava o oferecimento de assistência médica aos infectados pelo vírus.

Sem a produção de resultados significativos para a prevenção do HIV/ AIDS, em 1988, o PN-DST/ AIDS recebeu a tripla missão institucional de coordenação, elaboração de normas técnicas e formulação de políticas públicas. Apenas no início da década de 1990 o programa tornou-se bem estruturado com a realização de medidas mais decisivas do governo (Simões, 1997). Impulsionada por diversos setores, a resposta governamental foi centrada em ações integradas de âmbito preventivo e assistencial, articuladas aos princípios de universalidade, integralidade e equidade do Sistema único de Saúde (SUS).

Nesse momento ocorreu a reflexão sobre os princípios que nortearam a implantação e consolidação dos centros de testagem, resultando em novas propostas, diretrizes de trabalho e na mudança, em 1997, do nome COAS para Centros de Testagem e Aconselhamento (CTA). A alteração do nome também decorreu da dificuldade de compreensão da expressão Centros de Orientação e Apoio Sorológico e, implícito aí, um erro semântico (apoio sorológico) (Costa, 2004; Brasil, 1999b).

O MS lançou o "Manual de Aconselhamento em DST, HIV e AIDS: diretrizes de procedimentos básicos", citando o aconselhamento como importante estratégia para otimizar ações preventivas e terapêuticas (Araújo, 2003b). A confidencialidade e o aconselhamento tornaram-se requisitos imprescindíveis dos CTA, e suas ações voltadas à prevenção das DST/AIDS, promoção à adoção de práticas sexuais mais seguras e redução dos danos à saúde pelo uso indevido de drogas (Costa, 2004; Brasil, 1999b).

A prática de aconselhamento se fundamentou em três componentes: apoio emocional, apoio educativo com troca de informações $e$ avaliação de riscos. Suas etapas foram divididas em aconselhamentos pré e pós-teste, de modo a possibilitar uma interlocução entre o profissional e o usuário e a delinear medidas preventivas viáveis de acordo com as singularidades e visão de mundo dos sujeitos.

Segundo o manual de diretrizes dos CTA, o aconselhamento pré-teste pode ser trabalhado em situações individuais e/ou coletivas. É um momento para a troca de informações sobre: o sistema de testagem; o significado $e$ impacto de um possível resultado positivo; a infecção, transmissão, prevenção e diferença entre HIV e AIDS (Brasil, 1999b). Compreende ainda: o reforço à necessidade de adoção de práticas seguras frente ao HIV, com demonstração dos insumos de prevenção; consideração das possíveis reações emocionais que venham a ocorrer durante o período de espera do resultado do teste; estímulo a ponderar a realização ou não do teste; apoio emocional e verificação de redes sociais de apoio disponível do usuário (família, 
parceiros, amigos etc.). Nos serviços em que o pré-teste é abordado de forma coletiva cabe, ainda, resguardar a privacidade de cada membro, identificar $e$ acolher a demanda do grupo e utilizar linguagem compatível com o entendimento dos participantes.

O pós-teste, momento de entrega do resultado, é necessariamente acompanhado de aconselhamento individual. Para os casos de soronegatividade, deve-se fazer uma avaliação e uma orientação sobre a janela imunológica com possível necessidade de retestagem; lembrar que o resultado negativo não significa imunidade; reforçar quanto às práticas seguras já adotadas ou não e quanto ao uso correto dos insumos de prevenção (Brasil, 1999b).

Diante de um resultado positivo, são necessários: apoio emocional $e$ disponibilidade de tempo para assimilação do impacto do diagnóstico; desmistificar sentimentos que associam HIV/AIDS a culpa, rejeição, punição, morte e outros; informação sobre o tratamento, encaminhamento para o serviço de atendimento especializado (SAE); reforço à necessidade de adoção de práticas seguras para a redução de riscos de reinfecção e transmissão a outros; ênfase na importância do resultado ser comunicado ao(s) parceiro(s) sexual(ais); e definir com o cliente os serviços de assistência necessários, incluindo grupos de apoio (Brasil, 1999b).

Para um resultado indeterminado ou inconclusivo, são necessários apoio ao cliente, orientações sobre o exame e o reforço à adoção de práticas seguras (Brasil, 1999b). Como parte do programa de aconselhamento nos serviços de testagem, o MS implantou a ficha de Atendimento do Sistema de Informação (SI-CTA), quando perguntas predeterminadas são dirigidas ao usuário no atendimento individual, com o objetivo de caracterizar a clientela e conhecer melhor a epidemia.

As etapas do aconselhamento delineadas dessa forma destinavam-se à participação ativa do sujeito na prevenção, bem como à criação de um contexto onde ele pudesse ser ouvido e auxiliado. Objetivavam, também, a construção de um plano de redução de riscos em que se considerassem questões de gênero, diversidade sexual e uso de drogas, seguindo uma tendência moderna e democratizante ao responder às demandas $e$ expectativas dos clientes de forma menos hierárquica.

\section{Aconselhamento: uma prática "polifônica"}

Das cinco áreas de "democratização discursiva" apresentadas por Fairclough (2001), o aconselhamento parece influenciado, ou melhor, colonizado por três delas: no "acesso a tipos de discurso de prestígio", na "eliminação de marcadores explícitos de poder em tipos de discurso institucionais com relações desiguais de poder", e com tendência à "informalidade das línguas".

Ligado a esse primeiro item, o autor faz referência às conquistas advindas de lutas sociais que permitiram uma democratização de acessos a tipos de discurso de prestígio para indivíduos considerados de menor prestígio $e$ poder. Refere-se, ainda, ao acesso a instituições e posições dentro delas trazendo, como exemplo, o aumento no número de mulheres que conquistaram espaço no ensino superior. Do mesmo modo, essa conquista 
pode ser estendida aos avanços na participação de representantes populares no planejamento e na gestão das políticas públicas de saúde e, em especial, no PNDST/AIDS (Silva, 1998).

No aconselhamento pode-se destacar a abertura direta às informações devido ao empenho dos aconselhadores em explicar terminologias e temas referentes às DST/HIV/AIDS. Os usuários, por sua vez, passam a ter conhecimento e a fazer uso de termos reservados, apenas, aos cidadãos de prestígio. Além disso, são instituídos, de algum modo, como sujeitos de poder e decisão sobre sua própria saúde. Do ponto de vista do discurso institucional, é inequívoco o espaço aberto ao diálogo, mas, existe, também, uma certa solidez que, muitas vezes, dificulta esse diálogo, na medida em que os projetos são submetidos às racionalidades das ações públicas (Silva, 1998).

Numa área de grande interesse nesse estudo está "a eliminação de marcadores explícitos de hierarquia e assimetria de poder em tipos de discurso institucionais nos quais as relações de poder são desiguais” (Fairclough, 2001, p.250). O autor faz referência ao contraste existente entre a entrevista médica padrão e as práticas mais 'modernas', que revelam tendências à eliminação do controle: dos tópicos discutidos por meio de ciclos de pergunta-resposta-avaliação; dos sistemas de turnos conversacionais; e da natureza das perguntas, como as do tipo 'sim/não'. Entre outros tipos de marcadores que tendem a ser eliminados estão as formas assimétricas de tratamento, o uso de verbos diretivos ou imperativos e de vocabulários especializados inacessíveis ao outro.

Nesse contexto, o aconselhamento se configura como uma conversa na qual o usuário pode propor e discutir temas com base em seus interesses e necessidades. Evita-se a utilização abusiva de termos técnicos procurando-se uma abordagem mais direcionada ao entendimento/vocabulário do usuário. Sob outro aspecto, verifica-se que assimetrias permanecem, já que o aconselhamento é organizado discursivamente como uma investigação da vida do sujeito com perguntas predeterminadas e um controle da interação. $\mathrm{O}$ profissional aconselhador, por exemplo, é a pessoa que regularmente formula $e$ resume o que se disse na interação e que oferece a versão do que ocorreu. Dessa forma, pode-se dizer que algum tipo de controle interacional sob o usuário é ainda mantido, porém realizado de uma forma indireta, não característica ou ambivalente.

Para Fairclough (2001), essa tendência em eliminar marcadores de poder pode ser, de fato, apenas aparente, mas pode ser também substancial. Existe uma luta sobre o significado desse modo de democratização, ao se identificar que a eliminação de marcadores explícitos de poder pode estar intimamente ligada à terceira tendência a que se refere o autor: a informalidade. É assumindo um caráter cada vez mais conversacional, típico dos valores culturais contemporâneos, que o discurso vem se projetando de seu domínio primário, das interações pessoais da esfera privada para a esfera pública.

A tendência de informalidade da língua envolve desde questões ligadas ao conteúdo do discurso da mídia até a pressão, na indústria de serviços, para tratar esses serviços como bens e os clientes, como consumidores. Isso evidencia uma mescla de práticas discursivas de prestação de informações, de publicidade e mudanças nas identidades sociais de profissionais e seus clientes, 
assim como na natureza da interação entre eles. Uma variedade de tipos de entrevista e outros tipos de encontro, como, por exemplo, entre médicos e pacientes, tornaram-se também mais conversacionais. Essa mudança vai ao encontro das modificações "gerais nos valores culturais dominantes em nossa sociedade, que desvalorizam o elitismo profissional e estabelecem um alto valor para a informalidade, para a naturalidade e para a normalidade" (Fairclough, 2001, p.187).

Na prática de aconselhamento, a manifestação da informalidade e do que Fairclough (2001) chama de conversacionalização é identificada quando se trabalha a história de vida dos usuários e suas condições de vulnerabilidade de forma íntima e confidencial (Brasil, 1999a). Enfatiza-se a concessão aos clientes do espaço para falar, mostrando-se empatia em relação a seus relatos. Trata-se de transformações

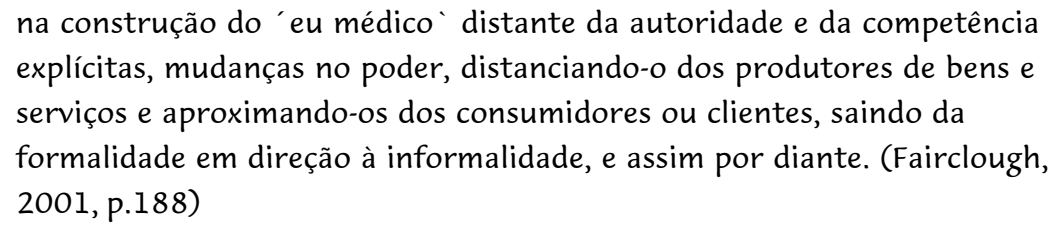

Uma outra forma de analisar o aconselhamento é percebê-lo sob a influência da tecnologização, segunda macrotendência identificada por Fairclough (2001) para entender as ordens de discurso modernas. A tecnologização influencia a prática de aconselhamento na medida em que esta se configura como um instrumento de ação estratégica. Os mecanismos de controle da vida das pessoas são organizados por procedimentos que se ordenam e se configuram por meio de sistemas de poder-saber (Foucault, 2006, 2005a, 2005b). A visão da natureza do poder nas sociedades modernas, desenvolvida por Foucault em seus estudos genealógicos, "localiza o discurso e a linguagem no coração das práticas e dos processos sociais" (Fairclough, 2001, p.75). Para Foucault (2006), as duas principais tecnologias de poder, enquanto formas de interpelação dos sujeitos na modernidade, são a disciplina e a confissão.

A respeito da disciplina, Foucault (2006) comenta que importa investigar como as técnicas trabalham sobre os corpos, isto é, como elas se organizam para o controle das disposições dos hábitos e dos movimentos do corpo. Esse controle dá origem ao que o autor chama de "corpos dóceis", isto é, adaptados às demandas das formas modernas de produção econômica.

$\mathrm{O}$ autor ressalta que, embora em qualquer sociedade o corpo tenha sido objeto de investimentos impostos por limitações e obrigações, há nesses esquemas de docilidade, em que o século XVIII teve tanto interesse, aspectos inovadores. Trata, por exemplo, de trabalhar o corpo detalhadamente, exercer sobre ele uma coerção sem folga e ter, como fim principal, um aumento do domínio de cada um sobre seu próprio corpo. Para Fairclough (2001), embora a disciplina seja uma tecnologia para lidar com as massas, ela funciona de forma altamente individualizada na medida em que isola, focaliza e assujeita cada indivíduo aos mesmos procedimentos normalizadores.

É a partir dos séculos XVII e XVIII, respectivamente, que os processos disciplinares se tornaram fórmulas gerais de dominação centrada no corpo 
como máquina e interligando-se, posteriormente, ao corpo-espécie. Esta grande tecnologia de duas faces - anatômica e biológica, individualizante e especificante - é direcionada à administração dos corpos e à gestão calculista da vida, abrindo a era de um "biopoder" (Foucault, 2005a). No corpo como máquina, a administração dos corpos: seu adestramento e sua integração em sistemas de controle eficazes, assegurados por procedimentos de poder disciplinar. No corpo-espécie, a gestão calculista da vida: a proliferação, o nascimento e a mortalidade, assumidos mediante uma série de intervenções $e$ regulações da população.

Essas duas direções são articuladas na forma de agenciamentos concretos que constituíram a grande tecnologia do poder no século XIX, que irá investir sobre o corpo, a saúde, as maneiras de se alimentar, de morar, as condições de vida e todo o espaço da existência. Um poder dessa natureza tem de qualificar, medir, avaliar, hierarquizar e operar em torno da norma. Nele "a instituição judiciária se integra cada vez mais num contínuo de aparelhos (médicos, administrativos etc.) cujas funções são sobretudo reguladoras" (Foucault, 2005a, p.135).

A disciplina é a técnica específica de um poder que toma os indivíduos, ao mesmo tempo, como objetos e instrumentos de seu exercício. Trata-se de um poder discreto, modesto e permanente, que se deve "ao uso de instrumentos simples: o olhar hierárquico, a sanção normalizadora e sua combinação num procedimento que lhe é específico, o exame." (Foucault, 2006, p.143).

O exame introduz a produção de registros sobre as pessoas, tornando-as objetos descritíveis, analisáveis e sujeitas à manipulação, para que, com base no levantamento de suas individualidades, se chegue às generalizações sobre populações, médias e normas. Para Fairclough (2001), no exame se incluiria a produção de registros por meio de exames médicos, exames educacionais $e$ muitas variedades de entrevistas. Sua sanção normalizadora não se destina à expiação ou à repressão, ela põe em funcionamento as operações distintas de: "relacionar os atos, os desempenhos, os comportamentos singulares a um conjunto, que é ao mesmo tempo campo de comparação, espaço de diferenciação e princípio de uma regra a seguir" (Foucault, 2006, p.152). Segundo o autor, o próprio sistema de classificação vale como recompensa ou punição.

No exame, se reúnem a demonstração de força, o estabelecimento da verdade e os jogos de perguntas e respostas sob um mecanismo que une uma formação de saber a uma forma de exercício do poder. $\mathrm{O}$ autor ressalta que o poder nem sempre deve ser descrito como algo negativo. "Na verdade o poder produz; ele produz realidade; produz campos de objetos e rituais da verdade. $O$ indivíduo e o conhecimento que dele se pode ter se originam nessa produção" (Foucault, 2006, p.161).

$\mathrm{O}$ aconselhamento na prevenção do HIV pode ser visto como uma estratégia de poder disciplinar e de regulação da população, na medida em que é regido por diretrizes e procedimentos básicos, estabelecidos pela PNDST/AIDS, e que interpela os sujeitos, em vários momentos, com o uso de mecanismos reguladores e corretivos. As etapas de pré e pós-teste são realizadas compulsoriamente determinando que o sujeito/corpo assista a um atendimento coletivo, comumente denominado "palestra" e seja, 
posteriormente, investigado sobre sua vida particular, fornecendo detalhes de sua prática sexual e sobre os riscos por ele atribuídos a seu(s) parceiro(a)s.

Ao responder às questões da ficha de Sistema de Informação do MS, os usuários são constituídos como sujeitos/casos descritíveis, analisáveis e generalizáveis. São classificados, por exemplo, por meio de um recorte populacional, como pertencentes à população geral ou a outros grupos específicos, como os de confinados, caminhoneiros, trabalhadores do sexo e homens que fazem sexo com homens. Existe, ainda, a identificação/ classificação pelo relato quanto ao número e tipo de parceiros sexuais, se homens, mulheres ou ambos, e não exclusivamente pelo tipo de exposição ou situação de vulnerabilidade.

Sob esse aspecto, o aconselhamento realizado nos serviços de testagem parece também influenciado pela técnica da confissão. Nele, existe uma instância que requer a confissão, que avalia os riscos de infecção pelo HIV $e$ que "propicia a reflexão sobre valores, atitudes e condutas, incluindo o planejamento de estratégias de redução de risco" (Brasil, 1999a, p.11).

Para Foucault (2005a), a prática de aconselhamento está associada, em grau significativo, à técnica da subjetivação da confissão, na medida em que ela é usada para trazer o interior das pessoas para dentro do domínio poder-saber. Segundo o autor, a confissão, no Ocidente, passou a ser uma técnica altamente valorizada para produzir a verdade e permitir esse mergulhar em si mesmo; e falar, especialmente, sobre o sexo, ao ser colocado como um campo de alta fragilidade patológica, superfície de repercussão para outras doenças e como centro de uma nosografia própria: do instinto, das tendências, da imagem, do prazer e da conduta. A obtenção da confissão $e$ seus efeitos são recodificados na forma de operações terapêuticas $e$ intervenções médicas, revelando-se indispensável ao diagnóstico e à cura (Foucault, 2005b).

Originalmente, a confissão era uma prática utilizada na religião, se estendendo, posteriormente, à medicina, à educação, às relações de família, às variedades de aconselhamento, aos relacionamentos amorosos, e assim por diante. Ela ganhou status científico no século XIX, combinando-se ao exame para uso em interrogatório, no questionário exato e na hipnose. A confissão é como um
ritual de discurso onde o sujeito que fala coincide com o sujeito do enunciado; é também um ritual que se desenrola numa relação de poder, pois não se confessa sem a presença ao menos virtual de um parceiro, que não é simplesmente o interlocutor, mas a instância que requer a confissão, impõe-na, avalia-a e intervém para julgar, punir, perdoar, consolar, reconciliar. [...] Produz em quem a articula modificações intrínsecas: inocenta-o, resgata-o, purifica-o, livra-o de suas falhas, libera- o, promete-lhe a salvação. (Foucault, 2005a, p.61)

Segundo Giddens, no entanto, é incorreta a associação da terapia e do aconselhamento à técnica da confissão e considerá-la como um processo que surge como uma intrusão determinada e direta do "poder-conhecimento" na 
organização social, defendida por Foucault. Sem negar a conexão com o poder, o autor prefere considerá-la "como um fenômeno de reflexividade institucional em constante movimento" (Giddens, 1993, p.39).

Para esse autor, a expansão da reflexividade institucional é uma característica distintiva das sociedades modernas e é fundamental seu caráter "aberto" da auto-identidade e a natureza reflexiva do corpo. Isso proporciona um ímpeto básico às mudanças que ocorrem nos contextos pessoais, e também globais, da ação. Não se trata de um processo mecânico ou necessariamente controlador. O eu é, para todos, um projeto reflexivo/ interrogativo mais ou menos contínuo do passado, presente e futuro. "É um projeto conduzido em meio a uma profusão de recursos reflexivos: terapia e manuais de auto-ajuda de todos os tipos, programas de televisão e artigos de revistas" (Giddens, 1993, p.41).

$\mathrm{O}$ aconselhamento realizado nos CTA pode também ser considerado como uma forma de utilização da "tecnologia leve" que, segundo Merhy et al. (1997), estaria direcionada aos processos de gestão do cuidado e de reestruturação produtiva do setor saúde. No território dessas "tecnologias leves", seria priorizada a produção de vínculos, acolhimento $e$ autonomização nas decisões dos usuários. Para Deslandes (2005), haveria ainda uma gestão de processo de trabalho voltada à utilização da tecnologia de escuta e de negociação das regras comportamentais e organizacionais, trazendo a idéia da humanização e de melhoria da qualidade de atendimento.

O termo humanização é empregado no SUS como uma nova práxis, fundamentada na valorização dos diferentes sujeitos implicados no processo de produção de saúde - usuários, trabalhadores e gestores (Deslandes, 2005; Brasil, 2004b).

A humanização é vista como uma capacidade de articular os avanços tecnológicos com o bom relacionamento, com o objetivo da melhora na qualidade dos serviços prestados em saúde (Deslandes, 2005). Segundo a autora, a construção desse olhar ampliado exige uma mudança cultural $e$ estrutural que inclua a incorporação das "tecnologias leves" no arsenal dos saberes e competências de saúde, na valorização/reconhecimento das expressões, expectativas e demandas dos usuários do serviço.

$\mathrm{Na}$ visão de Fairclough (2001), o aconselhamento é altamente ambivalente, com orientações contraditórias para a dominação $e$ emancipação. Para Foucault (2005a), existe uma 'polivalência tática dos discursos', que permite que discursos diferentes e até contraditórios possam existir dentro de uma mesma estratégia. Para esse autor, "o discurso veicula e produz poder; reforça-o mas também mina, expõe, debilita e permite barrá-lo" (Foucault, 2005a, p.96).

É importante ressaltar que, independentemente da forma com que cada um desses autores representa o aconselhamento, existe, nessa prática, toda uma política de intervenções permanentes em nível do corpo, das condutas, da saúde e da vida quotidiana em sua realização, que sinaliza para a necessidade de analisar seus efeitos enquanto prática ideológica-discursiva. Isso sugere que existe uma relação dialógica entre os sujeitos sociais e os processos constitutivos do discurso. Assim, os sujeitos são capazes de 
resistir, interferir e negociar com os variados tipos de discursos materializados nessa interação.

\section{Considerações finais}

Identificar a formação dos discursos sobre a AIDS, a que necessidades eles responderam, como se modificaram e se deslocaram, tem importância central para se compreender a prática do aconselhamento. O deslocamento do conceito de grupo de risco para o de comportamento de risco, chegandose à noção de vulnerabilidade, resultou na construção do aconselhamento como uma alternativa para o enfrentamento da infecção pelo HIV.

Enquanto prática, o aconselhamento contempla temas importantes como a tecnologização, a reflexividade, o diálogo, o respeito e a confiança. Nesse contexto, parece, de fato, existir nele um jogo de ambigüidades entre os sistemas democrático e coercitivo, conjugando modos informais $e$ regulatórios. Isto porque, para atingir seus objetivos de prevenção $e$ promoção da saúde, ele, muitas vezes, se revela como o próprio ato de aconselhar no sentido normalizador de condutas. Em outros momentos, mostra-se como uma prática de tendência à eliminação de marcadores explícitos de poder, pautada em prerrogativas éticas, humanistas $e$ democráticas.

Como propósito institucional, trata-se de uma estratégia de atenção integral direcionada ao fomento da autonomia e do protagonismo dos sujeitos no processo de produção de saúde e de prevenção ao HIV/AIDS. Sob outro aspecto, o discurso do aconselhamento parece trazer a ambigüidade típica de uma sociedade fragmentada e, portanto, complexa no sentido da sua não homogeneidade ou contradição. Nesse contexto, pode-se pensar a complexidade do aconselhamento na prevenção do HIV como uma grande engrenagem em que diferentes discursos podem existir dentro de uma mesma estratégia, conjugando modos liberadores e disciplinares. Isso significa que essa própria ambigüidade pode revelar um potencial de mudança frente às discussões que envolvem a autonomia dos sujeitos na prevenção das DST/HIV/AIDS.

Compreender o aconselhamento sob o ponto de vista dessa ambigüidade remete aos questionamentos: como os usuários do serviço passam por esta experiência que coaduna aspectos democratizantes e coercitivos? Quais os significados atribuídos por eles ao aconselhamento realizado? O que o caráter confessional, de informalidade e diálogo, assim como os aspectos disciplinar e normativo têm em comum com os apelos e as características desses usuários? Responder a essas perguntas nos coloca diante de um caminho ainda pouco investigado, que se pretende abordar em futuros estudos. Para se abrir espaço à reflexividade, com vistas às transformações propostas no campo preventivo, é fundamental que se compreenda que os objetivos e diretrizes inerentes à prática do aconselhamento necessitam de respaldo no outro, a quem a proposta é dirigida. 


\section{Agradecimentos}

A Claudia Natividade, do Instituto Mineiro de Saúde Mental e Social (Albam) de Belo Horizonte, pela contruibuição teórica. Ao professor Renarde Freire Nobre, do Departamento de Sociologia e Antropologia da UFMG, e Luiz Carlos Brant Carneido, da Interfaz Promoção da Saúde, pela leitura crítica do texto.

\section{Referências}

ARAÚJO, C.L.F. A prática de aconselhamento em DST/AIDS e a integralidade. In: PINHEIRO, R.; MATTOS, R.A. (Orgs.). Construção da integralidade: cotidiano, saberes e práticas em saúde. Rio de Janeiro: IMS/ ABRASCO, 2003a. p.145-68.

Aconselhadores, acolhedores: a prática de aconselhamento em DST/AIDS em um CTA do estado do Rio de Janeiro. 2003b. Tese (Doutorado) - Instituto de Medicina Social, Universidade do Estado do Rio de Janeiro, Rio de Janeiro.

AYRES, J.R.C.M.; FRANÇA JR., I.; CALAZANS, G.J.; SALETTI FILHO, H.C. O conceito de vulnerabilidade e as práticas de saúde: novas perspectivas e desafios. In: CZERESNIA, D.; FREITAS, C.M. (Orgs.).

Promoção da saúde: conceitos, reflexões, tendências. Rio de Janeiro: Fiocruz, 2003. p.117-39.

BAHKTIN, MM. Os gêneros do discurso. In: Estética da criação verbal. 2.ed. São Paulo: Martins Fontes, 1997. cap. P. 279-326

BRASIL. Ministério da Saúde. Portal da Saúde. Histórico do Programa Nacional de DST e AIDS. Brasília: Ministério da Saúde, 2007. Disponível em: <http//:www.portal.saude.gov.br/portal/aplicacoes/noticias/ noticias_detalhe.cfm?co_seq_noticia=29718>. Acesso em: 19 jun. 2007.

. Ministério da Saúde. Secretaria de Vigilância em Saúde. Programa Nacional de DST/AIDS. Priorizar a inserção do diagnóstico do HIV e aconselhamento na rotina da rede básica no âmbito do processo de descentralização. Disponível em: <http://www.dtr2004a.saude.gov.br/.../documentos/segunda\%20mostra/ aconselhamento_dst_hiv_atencao_basicadenise_serafim.pdf>. Acesso em: 20 abr. 2007.

. Ministério da Saúde. Secretaria Executiva. Núcleo Técnico da Política Nacional de Humanização. A humanização como eixo norteador das práticas de atenção e gestão em todas as instâncias do SUS. Brasília: Ministério da Saúde, 2004b. Disponível em: <http://www.dtr2001.saude.gov.br/editora/produtos/ impressos/folheto/04_0923_FL.pdf>. Acesso em: 22 nov. 2005.

. Ministério da Saúde. Secretaria de Políticas de Saúde. Coordenação Nacional de DST e AIDS.

Aconselhamento em DST, HIV e AIDS: diretrizes e procedimentos básicos. 3.ed. Brasília: Ministério da Saúde, 1999a.

. Ministério da Saúde. Secretaria de Políticas de Saúde. Coordenação Nacional de DST e AIDS. Diretrizes dos Centros de Testagem e Aconselhamento (CTA): manual. Brasília: Ministério da Saúde, 1999b.

CECCATO, M.G.B.; ACURCIO, F.A.; BONOLO, P.F.; ROCHA, G.M.; GUIMARÃES, M.D.C. Compreensão de informações relativas ao tratamento anti-retroviral entre indivíduos infectados pelo HIV. Cad. Saúde Pública, v.20, n.5, p.1388-97, 2004.

COSTA, M.A.O. Aconselhamento para o teste anti-HIV: o olhar de profissionais de unidades básicas de saúde de Belo Horizonte. 2004. Dissertação (Mestrado) - Escola de Enfermagem, Universidade Federal de Minas Gerais, Belo Horizonte. 
DESLANDES, S.F. O projeto ético-político da humanização: conceitos, métodos e identidade. Interface Comunc., Saúde, Educ., v.9, n.17, p.401-3, 2005.

FAIRCLOUGH, N. Discurso e mudança social. Brasília: Editora UnB, 2001.

FILGUEIRAS, S.L.; DESLANDES, S.F. Avaliação das ações de aconselhamento: análise de uma perspectiva de prevenção centrada na pessoa. Cad. Saúde Pública, v.15, supl.2, p.121-31, 1999.

FOUCAULT, M. Vigiar e punir: nascimento da prisão. 31.ed. Petrópolis: Vozes, 2006.

A história da sexualidade, I: a vontade de saber. 16.ed. Rio de Janeiro: Graal, 2005a.

A arqueologia do saber. 7.ed. Rio de Janeiro: Forense Universitária, 2005b.

GIDDENS, A. Modernidade e identidade. Rio de Janeiro: Jorge Zahar, 2002.

A transformação da intimidade: sexualidade, amor e erotismo nas sociedades modernas. São Paulo: Editora Unesp, 1993.

MANN, J.; TARANTOLA, D.J.M., NETTER, T.W. (Orgs.). A Aids no mundo. Rio de Janeiro: Relume Dumará, 1993.

MATTOS, R.A. Integralidade e a formulação de políticas específicas de saúde. In: PINHEIRO, R.; MATTOS, R.A. (Orgs.). Construção da integralidade: cotidiano, saberes e práticas em saúde. Rio de Janeiro: IMS/ABRASCO, 2003. p.45-60.

MERHY, E.E.; CHAKKOUR, M.; STÉFANO, E.; STÉFANO, M.E.; SANTOS, C.M.; RODRIGUES, R.A.; OLIVEIRA, P.C.P. Em busca de ferramentas analisadoras das tecnologias em saúde: a informação e o dia a dia de um serviço, interrogando e gerindo trabalho em saúde. In: MEHRY, E.E.; ONOCKO, R. (Orgs.). Agir em saúde: um desafio para o público. São Paulo: Hucitec, 1997. p.113-50.

MINAYO, M.C.S.; SOUZA, E.R.; ASSIS, S.G.; CRUZ NETO, O.; DESLANDES, S.F.; SILVA, C..F.P. Avaliação dos Centros de Orientação e Apoio Sorológico/CTA/COAS da região nordeste do Brasil. Cad. Saúde Pública, v.15, n.2, p.355-67, 1999. Disponível em: <www.scielo.org/scielo>. Acesso em: 20 jun. 2005.

MONTEIRO, S. Qual prevenção? AIDS, sexualidade e gênero em uma favela carioca. Rio de Janeiro: Fiocruz, 2002.

PARKER, R.G. Na construção da Aids: sexualidade, intervenção, política. Rio de Janeiro/São Paulo: ABIA/Ed. 34, 2000.

A construção da solidariedade: Aids, sexualidade e política no Brasil. Rio de Janeiro: Relume Dumará/ABIA/IMS, UERJ, 1994.

PARKER, R.G.; CAMARGO JR., K.R. Pobreza e HIVIAIDS: aspectos antropológicos e sociológicos. Cad. Saúde Pública, v.16, supl.1, p.89-102, 2000.

SILVA, C.L.C. ONGs/AIDS, intervenções sociais e novos laços de solidariedade social. Cad. Saúde Pública, v.14, suppl.2, p.129-39, 1998.

SIMÕES, A.M. A representação da AIDS construída a partir das informações veiculadas nos jornais diários: análise da cobertura sobre AIDS no jornal "Estado de Minas". 1997. Dissertação (Mestrado) - Escola de Biblioteconomia, Universidade Federal de Minas Gerais, Belo Horizonte.

SOUZA, V.; FREITAS, M.I.F. Adolescentes, Aids e as campanhas na televisão. REME: Rev. Min. Enferm., v.6, n.1/2, p.2-6, 2002. 
SOUZA, V.; CZERESNIA, D. Consideraciones sobre los discursos de asesoramiento en los centros de pruebas anti-HIV. Interface - Comunic., Saúde, Educ., v.11, n.23, p.531-48, set/dez 2007.

El artículo analiza la incorporación de la práctica de asesoramiento en los centros de pruebas anti-VHI, como consecuencia de la construcción discursivo-social del SIDA, en el contexto de la modernidad tardía y a partir de la propuesta expresada por el Programa Nacional de DST/ SIDA brasileño. Tomándose como principal referencia analítica las influencias globales del proceso de democratización de discursos y prácticas modernas contextuadas por Fairclough. Se utiliza también como referencia teórica la evolución de los discursos preventivos transmitidos desde la identificación de la infección y de las tecnologías de poder disciplinar y de confesión. El asesoramiento contempla temas importantes como promoción tecnológica, reflexividad y diálogo; identificándose en él un juego de ambigüedades entre los sistemas democrático y coercitivo, conjugando modos liberadores y disciplinarios. Comprender el asesoramiento de esta ambigüedad genera cuestionamientos aún poco investigados. Es necesario pues entender la práctica del asesoramiento desde la perspectiva del usuario a quien se dirige la propuesta.

PALABRAS CLAVE: Aconsejar. Síndrome de Inmunodeficiencia Adquirida. Educación en Salud. 